\title{
Serious and Seriouser
}

\section{MISHA KAVKA}

UNIVERSITY OF AUCKLAND

\author{
Alexander R. Galloway \\ The Interface Effect \\ Polity Press 2012 \\ ISBN 9780745662527 (HB) 9780745662534 (PB) 9780745662923 (EB) \\ RRP \$94.95 (HB) \$31.95 (PB) \$25.99 (EB) \\ McKenzie Wark \\ Telesthesia: Communication, Culture and Class \\ Polity Press 2012 \\ ISBN 9780745653983 (HB) 9780745653990 (PB) \\ RRP \$105.95 (HB) \$33.95 (PB)
}

On the face of it, it makes perfect sense to review The Interface Effect and Telesthesia together. Published by the same press in the same year, both books offer a theoretical, broad-stroke critique of the role of digital information in the larger context of shifts in the cultural and political economy of 'overdeveloped nations'. (Wark) Both books ask, quite simply, how did we get to this particular juncture of 'culture in the age of information', (Galloway 54) and what does this culture demand of us as critics? For both authors the concept of the 'interface' plays a central 
function in this critique, a term defined by Galloway as the effect of 'being on the boundary' rather than 'a thing', (33) while Wark favours the term 'vector' to describe a similarly 'connective, abstracting kind of relation'. (13) Whether named the interface or the vector, both authors use the concept of thresholds and connectivity to illuminate the workings of what Galloway calls 'ludic capitalism' and Wark dubs the 'vectoralist class', which are different names for operations of mining power by 'coaxing new value out of raw, systemic interactions'. (Galloway 29) Although the two books draw on different philosophical underpinnings, both Wark and Galloway seek to reclaim a Freudian-Marxist (for Galloway) or solely Marxist (for Wark) tradition to mobilise 'the core act of critique'. (Galloway 27) It is not just the books, then, but the authors themselves who are deep in conversation, as is evident in the fact that the subsequent publication for each of them was the shared project, Excommunication: Three Enquiries in Media and Mediation, written with Eugene Thacker, with whom Galloway previously co-wrote The Exploit: A Theory of Networks. ${ }^{1}$

It is therefore not much of a stretch to imagine Galloway and Wark, who both teach in New York City, hunched together over coffee at an intellectual variant of Central Perk. Yet, when delving into the books, one is first struck by the differences between the projects and their respective tones. This difference goes beyond the stylistic to the approach itself, which is to say that style and substance are conjoined in both works, although perhaps in unexpected ways. Reductively put, one is a playful book about serious objects and the other is a serious book about playful objects. In his introductory chapter, 'How to Occupy an Abstraction', Wark sets out his aim for Telesthesia: to practice 'low theory', 'somewhere in the margins between institutional forms of writing', in a way that is 'speculative, playful, tactical'. (12) Galloway's work, by contrast, might fit better into what Wark calls High Theory (low theory is never capitalised), the kind of theory that lists proper names attached to institutional knowledge. Indeed, Galloway takes his-and our-intimate knowledge of the high theorists as a given, skipping effortlessly from the Greeks to twentiethcentury continental philosophers and twenty-first-century network theorists. Wark, on the other hand, states baldly in his chapter on object-oriented ontology, 'I am not a philosopher', (156) a statement enacted as much as underscored by his breezy rhetorical style and the subdivision of Telesthesia into nineteen short chapters, each 
with a disarmingly witty, enigmatic title (the second chapter is called 'Fresh Maimed Babies'). While Wark's first-person style trumpets the values that underlie his thinking, it also makes for a rollicking good read as far as intellectual heavy lifting goes. The short chapters, chatty anecdotes and deceptively simple sentences lend themselves to punchy, aphoristic observations about serious socio-political entanglements: 'The work of the military-entertainment complex is two-sided. It has its rational, logistical side; but is also has its romantic, imaginative side. The latter invents reasons for the former to exist.' (81) The Interface Effect, by contrast, sticks to four appropriately sized chapters, bookended by an introduction that begins with a return to Lev Manovich's The Language of New Media and a postscript that takes up the issues of race, class and identity politics in digital culture. ${ }^{2}$ Along the way, Galloway's style often bends under the effort of his thinking, even as he turns his attention to unexpectedly light objects of serious pop culture, like Norman Rockwell's self-portraiture, the massive multiplayer online game World of Warcraft, Frank Gehry's Stata Center on the MIT campus and the television series 24.

Wark secures his breezy text through a carefully chosen lexicon (complete with last-chapter glossary) of 'speculative terms, keys to possible realities' built around two recurring notions: the vector and antipodality. These terms, as with all of Wark's specialist vocabulary, are interconnected in a complex web of relations; thus, 'every vector creates a new antipode' (43) at the same time as every antipode is linked to its podal other through vectoral connections, which by the late twentieth century had become 'instant'. (47) Introduced as a relation, antipodality turns out also to be a way of doing criticism, a method that involves 'drifting along a moving and variable line' (10) which is 'anti' because it starts at the periphery and works toward the centre (11) through a series of 'plural elsewheres'. (28) This plurality plays out literally in the book, since every chapter has a subtitled location, for example, Sydney, Australia or Taipei, Taiwan (chapters 2 and 3). The location is important-even though Wark makes clear that antipodality operates simultaneously as place and abstraction, politics and indeterminacy-for it marks both the need and the rationale for including locatedness in the act of practicing 'low theory' on 'weird global media events', such as the Occupy movement begun in Zucotti Park, New York. Because of the determined indeterminacy associated with the vector, there is a slipperiness to antipodality which allows Wark both to claim 
his Australian roots and announce 'we are all antipodal'. (13) Locatedness is thus an abstraction - though not a universalising one, insists Wark-which allows the first part of the book to unfold as 'a psychogeography of the vector', to be followed by an evental analysis of the 'weird global media event' and finally by 'identifying new kinds of persona, or interface'. (88)

All three of these foci are given as methods for grasping the peculiar properties of what Wark dubs 'third nature'. Third nature is the emergent terrain arising from telesthesia, or perception at a distance via technologies of mediation, beginning with the telegraph ('the Victorian internet', as Wark wryly dubs it). If 'nature' is what we construct in retrospect as the tyranny of necessity associated with raw environments, then second nature is the collective production of a built environment that creates a partial freedom from necessity' through the social organisation of labour. Third nature, in turn, is 'the collective production of a communication environment that tries to overcome the new necessities imposed by the class relations of second nature'. (128) In Wark's schema, natural environment thus gives way to built environment, which is currently being reorganised as communication environment. Each of these environments is associated with its own ruling class, whose power lies in releasing a new 'productivity of nature' (109) through a particular set of property relations: the pastoralist class turns feudal peasants into tenant farmers through the privatisation of land; the capitalist class turns farmers into industrial workers through the privatisation of means of manufacture; and the 'vectorialist' class turns workers into information labourers through the privatisation of vectors of communication. (109-10) On one level, then, the message of Telesthesia is simple: it's (still) about class, stupid. For Wark, however, what has changed is the classes themselves: 'we live in an era when a new ruling class is emerging, one that requires a new form of private property', (93) or information itself. In turn, the vectoralist class, who fill the figurative shoes of the early twentieth-century fat cats chomping on cigars, requires a new labouring class who can wrest productivity from privatised information: the hacker class, a newly productive computer-age proletariat. The 'hacker' names not only a class but also a particular kind of interface linked to a particular mode of extracting productivity: 'The hacker hacks, producing new knowledge, new culture, new science-but does not own the means of realizing the value of what it creates. The vectoralist class 
produces nothing new' (143) but specialises in extracting value from the hacker's labour turned into intellectual property. This is techno-Marxism.

For Galloway the issue is similarly about politics but in a more aesthetic mode. This is why he opens with Manovich, in order to frame the project through the aesthetics of new media while asking whether there is any politics to Manovich's approach. (9) The answer, in long form, is 'yes', though it requires a number of detours through mediation, ideology, unrepresentability and what he calls 'disingenous informatics' to describe 'what form art and politics take'. (30) The tool most consistently at Galloway's disposal is the interface, which functions variously as a verb to highlight 'how cultural production and the socio-historical situation ... are interfaced together', (30) as an allegorical device to describe, for instance, the relationship 'between subject and world, between surface and source', (54) and as a process of mediation that itself can take hard forms, such as the computer. (23) In all of these uses, the interface-or the intraface, which is the interface internal to the interface (40)—names the process by which 'local relationships ... create an externalisation, an incoherence, an edging, or a framing'. (36) In Galloway's schema of signification in the age of informatics, we are currently witnessing a shift from an ideological to an ethical regime of signification (with 'ethical' understood as ethos, or a set of principles for practice), whereby ideology gives way to its simulation and 'gets modeled in software'. (52) Within this shift the computer is the 'ultimate ethical machine' because it has only a virtual, rather than an actual, relation to ideology. (52) This does not mean the demise of politics, or even of ideology, but rather a shift in their representability, for the computer's ethos of transcoding or obfuscating code in the very process of turning data into information means that data are formless, without visualisation. This is what Galloway calls 'the dilemma of unrepresentability lurking within information aesthetics'. (86)

As part of this dilemma, Galloway and Wark share a central concern with control, or the control society's hand-in-glove operation with digitisation. For Wark, the danger of the digital has to do with the speed and degree to which it has been coopted by property and the strategies of privatisation that lie behind the ubiquity of competitive gameplay. For Galloway, who is similarly disturbed by ludic capitalism, the key problem is that 'we do not yet have a critical or poetic language in which to represent the control society' (98) and hence we have no way of visualising, or even 
speaking of, the 'point of power [which] today resides in networks, computer, algorithms, information, and data'. (92) Wark echoes the criticism in different terms, arguing that vectoral power can no longer be described by the panopticon, meaning a single point of surveillance of the many, but rather operates as a transopticon, or 'the editability of multiple flows of intelligence into a continuous feed'. (33) This continuous feed is synonymous with the means of control in the digital age: 'Control becomes a matter not just of the management of bodies and their wants, but a more subtle business of extracting the required salience from components of the human, wired in increasingly segmented ways into components of the digital'. (81) Welcome to 'the world made over as third nature'. (81)

Lest this critique appear too deterministic or too fatalist, both Wark and Galloway hold out the possibility of a solution of sorts in the form of the hacker and poetics, respectively. 'What might gives us hope', Wark writes, 'is the very fragility of the vectoralist position, which runs counter to the ontological properties of information itself', (147) precisely because information can 'always exceed any embodiment', any commodification. (155) If anyone, or any class, can capitalise (as it were) on this fragility then it will be hackers, those creators of new knowledge who have the capacity to counteract copyright by enacting 'copyleft' or 'copygift', which is Wark's term for the 'dialectical negation of intellectual property'. (168) Wark here returns to his polemic from The Hacker Manifesto, giving it the spin of accessibility as he addresses the hacker in all of us: 'Rip your CDs and share them with your friends. ${ }^{3}$ Plagiarise a few term papers while you are at it.' (155) Galloway is less cavalier, perhaps, but no less hopeful: his aim is to call, not for a return to cognitive mapping, since information interfaces are limited in their ability to provide orientation within the social totality, but rather for 'a poetics as such for this mysterious new machinic space'. (99) Although he admits that such an endeavour faces many challenges, Galloway's normally sober analysis vibrates into a clarion call: 'once the first few steps are taken, a wide-open plane emerges, a vast antihistory of informatics waiting to be written, a vast world of representation waiting to be inscribed'. (99) This moment, coming at the end of Chapter 3, is the climax of the book, not least because by the postscript Galloway seems to have lost his optimism: 'The virtual is no longer the site of emancipation ... Rather, it is the primary mechanism of oppression.' (138) 
In a sense, both texts end before they are over. When in Chapter 4 Galloway asks, 'Is 24 a political show?' and then follows with a postscript on the 'Chinese gold farmer' whose raced, classed and monetised spectre 'haunts the world of digital games', (121) he is half-heartedly attempting to inscribe a few of those aforementioned representations into the anti-history of informatics that awaits us. Wark hits his high mark of serious irreverence well before the end of Telesthesia, when he supplements object-oriented ontology, or (000), with his own pragmatic Marxist orientation newly dubbed 'praxis (object-oriented)', or P(00). (161) One rather hopes that came to him in a flash rather than after sleepless nights working it out. Once past the messy business of P(O0), however, Wark, too, has run out of steam except for a chapter that addresses the representational element left aside by Galloway-gender. Although neither book aims for gender critique, Wark's inclusion of it inadvertently raises a larger problem in both about departicularised or de-faced subjectivity. Wark's late chapter 'The Little Sisters Are Watching You' introduces a figure called 'The Girl' but immediately strips her of all particularity: she is 'not necessarily female or even all that young', not necessarily white or even human. (176-7) She is nothing in effect but the effect (or in psychoanalytic terms, the objectcause) of consumerist desire, a whatever girl. Having stripped her of gender, Wark then proceeds to strip away all the political issues that might tag along with gender:

the politics of domestic violence, rape, abortion, wage equality, sexual harassment in the workplace or on the street-the list goes on. Except that the Girl is one of the things that stands in the way of there even being a politics within which such things could be the stakes. (185-6).

In this view gender has so effectively turned itself into surface that it slips all of its own implications - which is where the problem lies.

Even subjects of the digitalised interface cannot so easily lose their hard-lived attunement to gender or race or class or ethnicity. This lack of embodied subjectivity is equally evident in Galloway, who makes the astute point that the stubborn logic of race 'can never be more purely actualized than in a computer simulation'. (132) but is nevertheless unwilling to allow for any subjective codification that is not automatically turned into financial value through being 'captured, massified, and scanned by systems of monetization'. (136) The only out, Galloway suggests, is escape into 'generic fullness' or Giorgio Agamben's 'whatever being' where 'the trick 
... is to abstain from the assignation of traits'. (140) I worry that in precisely this abstention from traits, assignations, characteristics and subjectivities, we find abstraction running roughshod over particularity. Ultimately there is in both texts a tendency toward explain-everything theorising, a logic of 'thusness' rather than 'thisness' (to adapt Galloway on haecceity, 139), as is evident in Galloway's unnerving tendency to use phrases like 'primordial axiom' and 'hence the following law'. $(52,86)$ It is this same logic of thusness that ungirls Wark's Girl and allows Galloway to collapse affect with identity before throwing out both with the bathwater of the consumer-clone subject. If this is what is involved in the 'quest for a new master code to unlock interface culture in general' (Galloway 101), then I confess I prefer working in bits. That digitised life suggests a master code to be cracked by critics of a Marxist stripe is a sleight of programming we should refuse. No doubt my view succumbs in character to what Galloway calls parochialism (31) and Wark bemoans as getting 'lost in the weeds of the everyday', (131) but I suspect that we disregard such detail at our peril. Whatever data my body might manifest online, I do not escape its local, particular and politicised purview.

Misha Kavka teaches media, film and television studies at the University of Auckland. She is the author of Reality Television, Affect and Intimacy (2008) and Reality TV (2012), and the co-editor of Gothic New Zealand: The Darker Side of Kiwi Culture (2006) and Feminist Consequences: Theory for the New Century (2001).

\footnotetext{
-NOTES

${ }^{1}$ Alexander R. Galloway, Eugene Thacker and Mackenzie Wark, Excommunication: Three Enquiries in Media and Mediation, University of Chicago Press, Chicago, 2013; Alexander R. Galloway and Eugene Thacker, Exploit: A Theory of Networks, University of Minnesota Press, Minneapolis, 2007.

${ }^{2}$ Lev Manovich, The Language of New Media, MIT Press, Cambridge, MA, 2001.

3 McKenzie Wark, The Hacker Manifesto, Harvard University Press, Cambridge, MA, 2004.
} 